\title{
Mengenal Alat Pemantau Gula Darah dari Air Liur dengan "On-Chip Electrochemical Sensing"
}

\begin{abstract}
Muhammad lqbalbin Mohd Yusof, Adam Renaldi, Ilham Septiandi, Budi Kurniawan, Ahmad Fauzi Mahasiswa Program Studi Sarjana, Fakultas Farmasi, UniversitasPadjadjaran, Sumedang, Jawa Barat.
\end{abstract}

Terbit online : 19 Juni 2016

\section{Abstrak:}

Glukosa juga dikenal sebagai gula darah maupun gula jagung menupakan salah satu monosakarida yang paling banyak dan penting terdistribusi di alam. Kadar glukosa yang berlebihan merupakan faktor resiko tinggi penykit diabetes pada manusia. Saat ini pemantauan kadar glukosa melalui darah telah menjadi satu-satunya yang diakui dan banyak digunakan sebagai metode untuk diagnosis dan pengelolaan diabetes. Penusukan jari juga dapat menyebabkan ketidaknyamanan sementara, memar, pingsan dan infeksi yang ditularkan melalui darah. Sebuah teknik non-invasif dan sederhana untuk diagnosis dan pemantauan diabetes sangat diinginkan. Salah satu metode yang digunakan untuk memantau kadar glukosa dalam saliva adalah dengan on-chip electrochemical sensing. On-chip electrochemical sensing memiliki keunggulan yaitu sederhana, sangat sensitif, akurat, nyaman, murah, dan secara efektif dapat menentukan konsentrasi glukosa dalam air liur.

Keyword: Gula darah, On-Chip Electrochemical Sensing, Glukosa

\section{Pendahuluan}

Glukosa juga dikenal sebagai gula darah maupun gula jagung merupakan salah satu monosakarida yang paling banyak dan penting terdistribusi di alam. Glukosa adalah sumber energi dari sel-sel hidup dan produk antara metabolisme.

\section{Dari pemantauan urin hingga gula darah}

Kadar glukosa yang berlebihan merupakan faktor resiko tinggi penyakit diabetes pada manusia. Pasien diabetes harus memantau glukosa darah secara teratur dan sering, tetapi metode konvensional pengambilan sampel darah yang telah berkembang sebelumnya untuk mengukur kadar glukosa pada umumnya menyakitkan. Sebelumnya, metode untuk menentukan kadar glukosa telah dikembangkan diantaranya adalah pendekatan optik, spektroskopi inframerah (IR), spektroskopi fluoresensi, spektroskopi Raman, pengukuran rotasi polarisasi optik dan metode elektrokimia.

Dahulu, orang menggunakan urin untuk melihat kadar gula, kemudian ditemukan bahwa korelasi antara urin dan glukosa plasma tidak konsisten. Sehingga saat ini pemantauan kadar glukosa melalui darah telah menjadi satu-satunya yang diakui dan banyak digunakan sebagai metode untuk diagnosis dan pengelolaan diabetes. Dalam pengujiannya, monitoring kadar gula darah ini harus dilakukan dengan cara menusuk jari pasien beberapa kali sehari dalam penggunaannya, dan hal ini merupakan masalah besar bagi anak-anak dan mengakibatkan konsekuensi negatif bagi manajemen penyakit. 


\section{Teknik non-invasif yang sederhana dalam pemantauan gula darah}

Penusukan jari juga dapat menyebabkan ketidaknyamanan sementara, memar, pingsan dan infeksi yang ditularkan melalui darah. Sebuah teknik non-invasif dan sederhana untuk diagnosis dan pemantauan diabetes sangat diinginkan. Dengan korelasi langsung antara glukosa darah dan glukosa saliva, adalah mungkin untuk hanya menerapkan pengukuran glukosa saliva untuk memantau kondisi kesehatan individu. Oleh karena itu, pemantauan kadar glukosa dengan sampel saliva dapat menjadi metode prediagnostik altematif untuk penderita diabetes dan indikatorkesehatan untukperorangan.

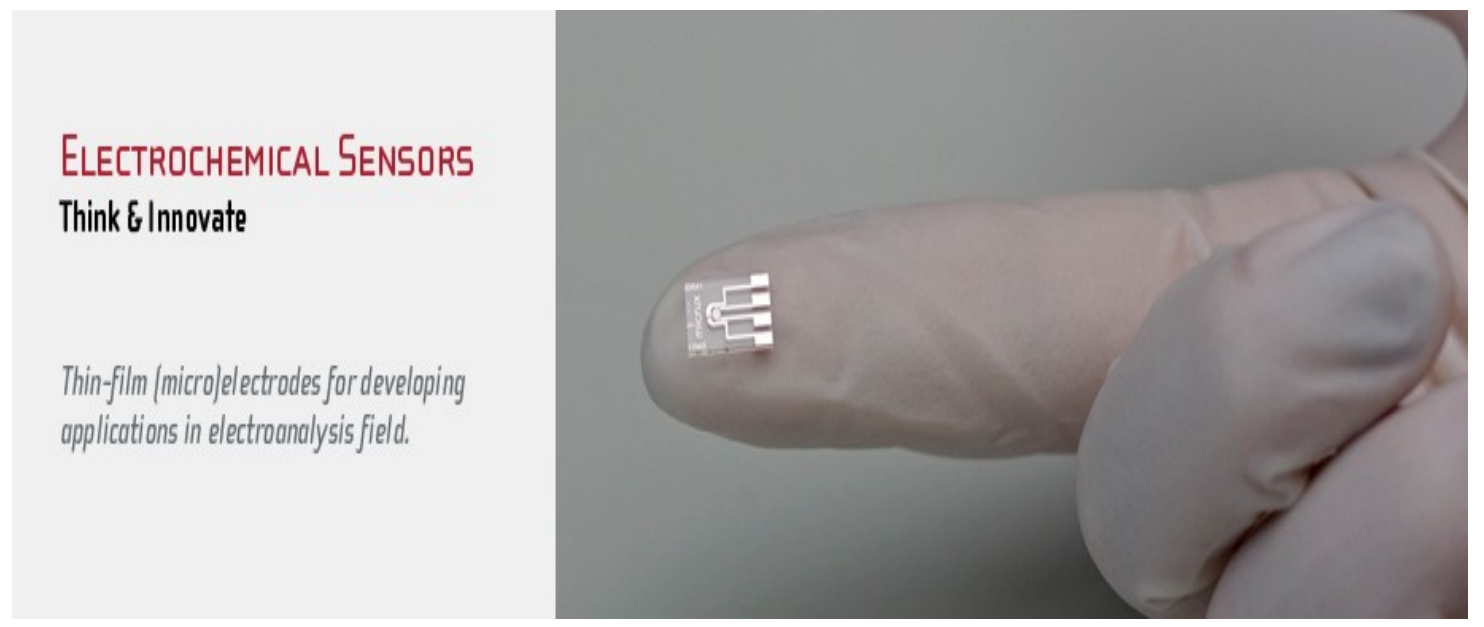

Gambar 1. Contoh sensor elektrokimia (pic : micruxfluidic.com)

Salah satu metode yang digunakan untuk memantau kadar glukosa dalam saliva adalah dengan on-chip electrochemical sensing. On-chip electrochemical sensing memiliki keunggulan yaitu sederhana, sangat sensitif, akurat, nyaman, murah, dan secara efektif dapat menentukan konsentrasi glukosa dalam air liur. Hal ini dibuat menggunakan mikro-fabrikasi dan prosedur perakitan LBL. Elektroda kerja difungsikan melalui layer-by-layer (LBL) perakitan nanotube karbon berdinding tunggal dan multilayer films composed of chitosan (CS), gold nanoparticles (GNp), dan glucose oxidase (Gox) untuk mendapatkan sensitivitas dan akurasi tinggi. Logam untuk semua elektroda adalah Pt yang secara luas dapat diaplikasikan dalam pemantauan glukosa.

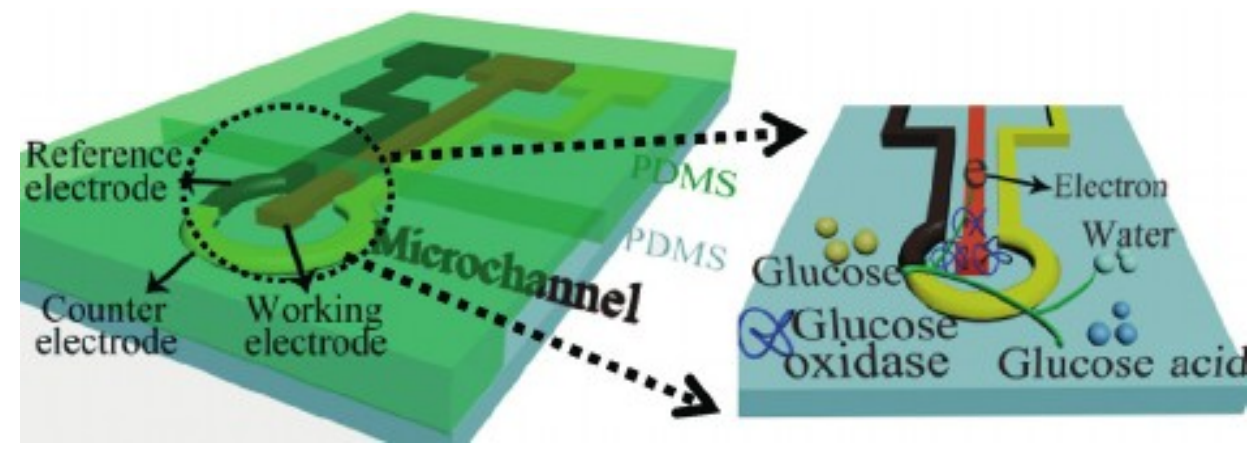

Gambar 2. Mekanisme sensor elektrokimia dalam chip 
Sensor glukosa yang dibuat, mendeteksi kadar glukosa dengan melacak elektron yang ditransfer langsung melalui GOx ke permukaan elektroda. Realisasi komunikasi listrik langsung dari GOx dengan permukaan elektroda tergantung pada jarak antara kofaktor redoks-aktif (FAD) dan permukaan elektroda. Selain itu, GOx asli saja tidak dapat mentransfer elektron ke permukaan elektroda konvensional karena perubahan konformasi enzim yang diperlukan untuk transfer elektron langsung yang dapat mengakibatkan hilangnya aktivitas enzimatik. Dalam penelitian, peneliti berusaha untuk membangun keseimbangan tersebut dengan memilih bahan yang mampu memfasilitasi transfer elektron langsung, misalnya, SWNT, dan GNP. Melalui hal tersebut telah dicapai sensitivitas yang tinggi tinggi dan akurasi penginderaan glukosa dalam sampel larutan PBS dan sampel air liur.

Pemantauan glukosa dilakukan dengan menggunakan sistem on-chip electrochemical sensing, melalui metode voltametri siklik elektroda Pt dimodifikasi dengan PAA/SWNT/(CS/GNp/GOx) 3 lapisan yang diperoleh di 0-40 mg/dL larutan glukosa dengan tegangan antara WE dan RE berkisar antara $-0,4 \mathrm{~V}$ ke $0,4 \mathrm{~V}$ pada tingkatscan $50 \mathrm{mV} / \mathrm{s}$.

\section{Kesimpulan}

Berdasarkan persenujuan Institutional Review Board (IRB) dari Northerastern University Human Subject Research Protection, pendeteksian glukosa ini tidak hanya dibandingkan dalam larutan penyangga PBS saja, tapi juga membandingkan glukosa darah satu subjek muda yang sehat diukur dengan meteran glukosa darah dan glukosa saliva oleh sensor tersebut dalam keadaan puasa pada hari yang berbeda.

Dilihat dari hasil percobaan tersebut, terdapat korelasi konstan yang jelas antara glukosa darah dan glukosa saliva pada keadaan puasa di hari yang berbeda. Hasil awal penelitian menunjukkan, glukosa saliva subjek muda puasa yang sehat pada kisaran $0,8-1,05 \mathrm{mg} / \mathrm{dL}$ sesuai dengan pengukuran menggunakan metode standar. Hal ini tidak hanya membuktikan sensor on chip electrochemical secara efektif dan andal dapat menentukan kadar glukosa dalam air liur, tetapi juga mengungkapkan adanya potensi besar penggunaan analisis air liur untuk kedua diagnosis non-invasive diabetes dan pemantauan glukosa.

\section{Daftar Pustaka}

[1] S. Vaddiraju et al., Technologies for continuous glucose monitoring: current problems and future promises, J. Diabetes Sci. Technol.4 (2010)1540-1562.

[2] E.-H. Yoo, S.-Y. Lee, Glucose biosensors: an overview of use in clinical practice, Sensors 10 (2010)4558-4576.

[3] Y.C. Shen et al., The use of Fourier-transform infrared spectroscopy for the quantitative determination of glucose concentration in whole blood, Phys. Med. Biol. 48 (2003) 2023-2032. [4] H.A. MacKenzie et al., Advances in photoacoustic noninvasive glucose testing, Clin. Chem. 45 (1999)1587-1595.

[5] X. Huang et al., A MEMS affinity glucose sensor using a biocompatible glucose- responsive polymer, Sens. Actuators B Chem. 140 (2009)603-609.

[6] S.-H. Jung, Y.-K. Lee, Y.-K. Son, Improved sensitivity of a glucose sensor by encapsulation of free GOx in conducting polymer micropillar structure, J. Electrochem. Sci. Technol. 2 (2011) $124-129$.

[7] A.P. Periasamy, Y.J. Chang, S.M. Chen, Amperometric glucose sensor based on glucose oxidase immobilized on gelatin-multiwalled carbon nanotube modified glassy carbon electrode, Bioelectrochemistry $80(2011) 114-120$.

[8] X.H. Kang et al., Glucose oxidase-graphene-chitosan modified electrode for direct electrochemistry and glucose sensing,Biosens. Bioelectron. 25 (2009) 
[9] J.T. Hayford, J.A. Weydert, R.G. Thompson, Validity of urine glucose measurements for estimating plasma-glucose concentration, Diabetes Care 6 (1983) 40-44.

[10] S. Amer et al., Salivary glucose concentrations in patients with diabetes mellitus - a minimally invasive technique for monitoring blood glucose levels, Pak. J. Pharm. Sci. 14 (2001) 33-37.

[11] C. Jurysta et al., Salivary glucose concentration and excretion in normal and diabetic subjects, J. Biomed. Biotechnol.2009 (2009) 6.

[12] A.M. Azevedo et al., Ethanol biosensors based on alcoholoxidase, Biosens. Bioelectron. 21 (2005)235-247.

[13] M. Ferreira et al., Enzyme-mediated amperometric biosensors prepared with the Layer-byLayer (LbL) adsorption technique,Biosens. Bioelectron. 19 (2004) 1611-1615.

[14] J. Zhang, M. Feng, H. Tachikawa, Layer-by-layer fabrication and direct electrochemistry of glucose oxidase on single wall carbon nanotubes, Biosens.Bioelectron.

$22(2007) 3036-3041$.

[15] A. Guiseppi-Elie, C.H. Lei, R.H. Baughman, Direct electron transfer of glucose oxidase on carbon nanotubes, Nanotechnology 13 (2002) 559-564.

[16] A. Harper, M.R. Anderson, Electrochemical glucose sensors-developments using electrostatic assembly and carbon nanotubes for biosensor construction, Sensors 10 (2010) 8248-8274.

[17] Y.H. Su et al., Electrochemical quartz crystal microbalance studies on enzymatic specific activity and direct electrochemistry of immobilized glucose oxidase in the presence of sodium dodecyl benzene sulfonate and multiwalled carbon nanotubes, Biotechnol. Progr. 24 (2008) 262-272.

[18] B.C. Janegitz et al., Direct electron transfer of glucose oxidase at glassy carbon electrode modified with functionalized carbon nanotubes within a dihexadecylphosphate film, Sens. Actuators B - Chem. 158 (2011) 411-417.

[19] L. Chen, W. Gorski, Bioinorganic composites for enzyme electrodes, Anal. Chem. 73 (2001) 2862-2868.

[20] B.Y. Wu et al., Amperometric glucose biosensor based on layer-by-layer assembly of multilayer films composed of chitosan, gold nanoparticles and glucose oxidase modified $\mathrm{Pt}$ electrode,Biosens. Bioelectron. 22 (2007) 838-844.

[21] L. Zhang et al., Attachment of gold nanoparticles to glassy carbon electrode and its application for the directelectrochemistry and electrocatalytic behavior of hemoglobin, Biosens.

Bioelectron.21 (2005)337-345.

[22] J.J. Feng et al., Direct electrochemistry and electrocatalysis of heme proteins immobilized on gold nanoparticles stabilized by chitosan, Anal.Biochem. 342 (2005)280-286.

[23] C. Chen et al., Recent advances in electrochemical glucose biosensors: a review, RSC Adv. 3 (2013)4473-4491.

[24] Y.-L. Yao, K.-K. Shiu, Direct electrochemistry of glucose oxidase at carbon nanotube- gold colloid modified electrode with poly(diallyldimethy- lammonium chloride) coating, Electroanalysis 20 (2008) 1542-1548.

[25] X.B. Yan et al., Transparent and flexible glucose biosensor via layer-by-layer assembly of multi-wall carbon nanotubes and glucose oxidase, Electrochem. Commun. 9 (2007) 12691275.

[26] W.W. Yang et al., Multilayered construction of glucose oxidase and gold nanoparticles on Au electrodes based on layer-by-layer covalent attachment, Electrochem. Commun. 8 (2006) $665-672$.

[27] J.-D. Qiu et al., Amperometric sensor based on ferrocene-modified multiwalled carbon nanotube nanocomposites as electron mediator for the determination of glucose, Anal. Biochem. 385 (2009) 264-269. 
[28] B.-Y. Wu et al., Amperometric glucose biosensor based on layer-by-layer assembly of multilayer films composed of chitosan, gold nanoparticles and glucose oxidase modified $\mathrm{Pt}$ electrode, Biosens. Bioelectron. 22 (2007) 838-844.

[29] X. Che et al., Amperometric glucose biosensor based on Prussian blue- multiwall carbon nanotubes composite and hollow PtCo nanochains, Electrochim. Acta 55 (2010) 5420- 5427.

[30] M. Lee et al., Enhanced sensitivity of a glucose sensor adopting polymermicrotubule, Mol. Cryst. Liq. Cryst. 492 (2008) 155-164.

[31] S. Mohtashami, M.R. Howlader, T.E. Doyle, Comparative electrochemical investigation of Pt $\mathrm{Au}$ and $\mathrm{Ti}$ electrodes on liquid crystal polymer for the application of neuromuscular prostheses, Ecs Trans. $35(2011) 23-33$.

[32] T.R.I.

gold and

Cataldi et al., modified platinumelectrodes

Comparison of silver, detection of iodide in urine samples following ion chromatography, J. Chromatogr. B Analyt. Technol. Biomed. Life Sci. 827 (2005)224-231.

[33] C. Jin, Z. Chen, Electrocatalytic oxidation of glucose on gold-platinum nanocomposite electrodes and platinum-modified gold electrodes, Synthetic Met. 157 (2007) 592-596.

[34] K.K. Kasem, S. Jones, Platinum as a reference electrode in electrochemical

measurements, Platin. Met. Rev. 52 (2008)100-106.

[35]W. Zhang, M.L. Wang, Saliva glucose monitoring system, 2014.US20140197 042 A1.

[36] T. Hoshi et al., Selective permeation of hydrogen peroxide through polyelectrolyte multilayer films and its use for amperometric biosensors, Anal. Chem.73 (2001) 5310-5315.

[37] $\mathrm{H}$. Huang, $X$. Yang.

Chitosan mediated assembly of gold nanoparticlesmultilayer, Colloids Surf., A 226 (2003)

77-86..

[38] F. Ricci et al., Prussian blue based screen printed biosensors with improved characteristics of long-term lifetime and pH stability, Biosens. Bioelectron.18 (2003) 165-174.

[39] J.H. Zhu et al., Planar amperometric glucose sensor based on glucose oxidaseimmobilized by chitosan film on Prussian blue layer, Sensors 2 (2002) 127-136.

[40] P. Marchetti et al., Salivary insulin concentrations in type 2 (non-insulin- dependent) diabetic patients and obese non-diabetic subjects: relationship to changes in plasma insulin levels after an oral glucose load,Diabetologia 29 (1986)695-698.

[41] M. Yamaguchi, M. Mitsumori, Y. Kano, Noninvasively measuring blood glucose using saliva, IEEE Eng. Med. Biol. 17 (1998) 59-63.

[42] M. Mitsumori, M. Yamaguchi, Y. Kano, A new approach to noninvasive measurement of blood glucose using saliva analyzing system, in: Proceedings of the 20th Annual International Conference of the IEEE Engineering in Medicine and Biology Society, 20, 1998, pp. 1767-1770.

[43] I. Mirzaii-Dizgah, M.R. Mirzaii-Dizgah, M.H. Mirzaii-Dizgah, Stimulated saliva glucose as a diagnostic specimen for detection of diabetes mellitus, J.Arch. Mil. Med. 1 (2013) 24-27.

[44] P. Abikshyeet, V. Ramesh, N. Oza, Glucose estimation in the salivary secretion of diabetes mellitus patients, Diabetes Metab. Syndr. Obes. 5 (2012)149-154.

[45] W. Zhang, Y. Du, M.L. Wang, Noninvasive glucose monitoring using saliva nanobiosensor, Sens. Bio-Sensing Res. 4 (2015) 23-29.

[46] Jianwei Wu, Ridong Wang, Haixia Yu, Guijun Li, Kexin Xu, Norman C. Tien, RobertC. Roberts and Dachao Li. Inkjet-printed microelectrodes on PDMS as biosensors for functionalized microfluidic systems. Lab Chip, 2015,15,690-695 